\title{
A NÃO-COINCIDÊNCIA INTERDISCURSIVA: \\ MARCA DA \\ RESPONSABILIDADE \\ ENUNCIATIVA \\ EM MONOGRAFIAS \\ DE CONCLUSÃO \\ DE CURSO \\ DE LETRAS
}

\author{
LA NO COINCIDENCIA INTERDISCURSIVA: MARCA DE RESPONSABILIDAD \\ ENUNCIATIVA EN MONOGRAFÍAS DE FINALIZACIÓN DEL CURSO DE LETRAS
}

\section{INTERDISCURSIVENON-COINCIDENCE: ENUNCIATIVERESPONSIBILITY MARKS IN LANGUAGE UNDERGRADUATE COURSE CONCLUSION MONOGRAPHS}

Ilderlândio Assis de Andrade Nascimento* Universidade Federal da Paraíba

RESUMO: Este trabalho analisa a não-coincidência interdiscursiva como marca da responsabilidade enunciativa em Monografias de Conclusão de Curso, a partir do quadro teórico da Análise Textual dos Discursos. O corpus desta pesquisa é constituído por 10 (dez) seções de revisão da bibliografia de monografias de conclusão de curso de Letras. A análise mostra a construção de sentidos do texto a partir do jogo entre atribuição e/ou assunção de pontos de vista, configurando-se aspecto constitutivo da natureza do gênero monográfico. Nesse sentido, a não-coincidência interdiscursiva é um modo de promover o diálogo com o outro na construção dos sentidos do texto, marcando, ao mesmo tempo, a responsabilidade enunciativa.

PALAVRAS-CHAVE: responsabilidade enunciativa; não-coincidência interdiscursiva; monografia de conclusão de curso.

* Doutorando pelo Programa de Pós-Graduação em Linguística (PROLING) da Universidade Federal da Paraíba (UFPB), JoãoPessoa,Paraíba,Brasil. E-mail: ilderlandionascimento@yahoo.com.br. 
RESUMEN: Este trabajo analiza la no coincidencia interdiscursiva como marca de la responsabilidad enunciativa en Monografías de Finalización del curso, desde el marco teórico de Análisis Textual de Discursos. El corpus en esta investigación consiste en diez (10) secciones de la revisión de literatura de monografías de finalización del curso de Letras. La análisis muestra la construcción de instrucciones de texto del juego entre misiones y / o asunción de puntos de vista, la creación de aspecto constitutivo de la naturaleza del género monográfico. En este sentido, la no coincidencia interdiscursiva es una manera de promover el diálogo con otros en la construcción de los sentidos de texto, marcando, al mismo tiempo, la responsabilidad enunciativa.

PALABRAS CLAVE: responsabilidad enunciativa; la no coincidencia interdiscursiva.;monografía de finalización del curso.

ABSTRACT: This paper, through the theoretical support of the Discourse Textual Analysis, looks into the interdiscursive noncoincidence as a mark of enunciative responsibility in undergraduate Course Conclusion Monographs. The corpus consists of ten (10) sections of literature review from monographs produced in a Language Undergraduate course. The investigation shows the text sense construction from the relation between attribution and/or assumption of points of view, which configures itself as a constitutive aspect of the monographic genre nature. In this regard, the interdiscursive non-coincidence is a manner of promoting the dialogue with the interlocutor (the other) in the text sense construction and, at the same time, of marking the enunciative responsibility.

KEYWORDS: enunciative responsibility; non-coincidence; conclusion course monograph.

\section{INTRODUÇÃO}

Pesquisas que tomam o texto acadêmico como objeto de estudo, nos mais variados aspectos, têm revelado um quadro preocupante, mostrando que são frequentes problemas tanto em relação ao manejo dos recursos linguístico-textuais necessários para a construção de textos coerentes, quanto em relação ao gerenciamento de outras vozes na rede textual discursiva (MATÊNCIO, 1997; BOCH; GROSSMAN, 2002; BESSA, 2007; PEREIRA, 2007; BERNARDINO, 2009; BESSA; BERNARDINO, 2011). Pesquisas como essas têm contribuído com importantes discussões sobre a produção, o ensino, a leitura e a circulação de textos no meio acadêmico, visto ser esse um espaço de(re)produção de conhecimento científico. Entre problemas verificados nos estudos que abordam a escrita acadêmica estão questões relacionadas ao introduzir, citar, comentar, parafrasear, explicar, retomar e desenvolver o dizer do outro na escritura de gêneros como artigos científicos, monografias, relatórios etc.

Entre os estudos que tomam o texto acadêmico como objeto de investigação, destacamos aqueles que seguem pressupostos da Linguística Textual (LT), mais precisamente no quadro teórico da Análise Textual dos Discursos (ATD), a partir da abordagem teórico-metodológica proposta por Adam (2008). Com relação a essa perspectiva de análise de textos, convém dizer que tem sido bastante produtiva no Brasil, como podemos citar, por exemplo, os estudos de Passeggi et al. (2010), de Rodrigues (2011), de Santos (2012), de Fonseca e Rodrigues (2012) e de Oliveira (2011). Esses estudos analisam, entre outros, textos/discursos políticos, literários, acadêmicos, jurídicos, jornalísticos.

$\mathrm{Na}$ linha desses estudos, este trabalho apresenta resultados da pesquisa desenvolvida durante a graduação em Letras e que resultou na monografia A responsabilidade enunciativa em monografias de conclusão de curso. Na investigação, objetivamos identificar, descrever e analisar a não-coincidência interdiscursiva como marca linguística-enunciativa da responsabilidade enunciativa na construção de seções de revisão bibliográfica de monografias de conclusão de curso de Letras. Assim, buscamos responder às seguintes questões: (a) que elementos linguístico-enunciativos materializam a não-coincidência interdiscursiva?; (b) como os elementos linguístico-enunciativos instauram a responsabilidade enunciativa?; (c) como os sentidos do gênero monográfico são construídos, considerando os aspectos linguístico-enunciativos da não-coincidência interlocutiva?

Metodologicamente, a pesquisa é do tipo documental, de natureza descritiva e interpretativa e orientada por uma abordagem qualitativa. Para constituir o corpus da pesquisa, selecionamos 10 (dez) seções de revisão bibliográfica de monografias produzidas 
por estudantes da Habilitação em Língua Portuguesa, no semestre 2009.2. As monografias foram coletadas na Biblioteca Pe. Sátiro Cavalcante Dantas, do Campus Avançado Profa. Maria Elisa de Albuquerque Maia (CAMEAM), da Universidade do Estado do Rio Grande do Norte (UERN). A escolha da seção de revisão bibliográfica se deu pelo fato de ser nela que o estudante traz para seu discurso outros discursos, outras vozes. É, também, nessa seção que o estudante dialoga com os estudos da área, como mostra a pesquisa de Bessa (2007).

Feita essa introdução, na seção seguinte, apresentamos o campo teórico da Análise Textual dos Discursos, conforme postulado por Adam (2008); logo depois, a partir de Adam (2008) e de Authier-Revuz (1998; 2004), discorreremos sobre a responsabilidade enunciativa, destacando os conceitos fundamentais dessa categoria, focando os fenômenos da modalização autonímica/nãocoincidências do dizer como pontos que assinalam a responsabilidade enunciativa; em seguida, faremos a análise dos dados, examinando fragmentos do corpus que revelam a materialização da responsabilidade enunciativa; por fim, faremos uma conclusão, ressaltando alguns resultados.

\section{SITUANDO A PESQUISA: A ANÁLISE TEXTUAL DOS DISCURSOS}

Nas linhas iniciais dessa discussão, vemos que, como o próprio Adam (2008) propõe, a ATD surge visando a responder questões não alcançadas pelas teorias existentes no campo dos estudos do discurso e do texto. Esse ponto é defendido por esse autor logo na introdução de sua obra A linguística textual: introdução à análise textual dos discursos e tem como fio condutor uma "[...] teoria da produção co(n)textual de sentidos, que deve fundar-se na análise de textos concretos.” (ADAM, 2008, p. 23).

Partindo dessa ideia basilar, constatamos que a proposta de Adam (2008) tem como ponto central analisar a produção social dos sentidos a partir de um conjunto de categorias textuais e discursivas, tendo como mediação os gêneros. Isso porque os discursos orais e escritos materializam-se nos mais diversos gêneros textuais. A proposta de Adam (2008) para a ATD permite-nos, portanto, trabalhar com os dois planos: o plano linguístico (como propõe a Linguística Textual) e o plano do discurso (como propõe a Análise do Discurso). Esses dois planos são apresentados pelo autor como sendo articulados. Essa articulação (LT e AD) permite ao analista abordar com mais propriedade a complexidade que é inerente a todo texto/discurso.

A proposta teórico-metodológica da ATD apresenta várias categorias de análise de textos. Entre essas categorias, encontramos aquela que tomamos como base para analisar o corpus dessa pesquisa: a responsabilidade enunciativa. A seguir, apresentamos algumas noções fundamentais acerca dessa categoria de análise.

\subsection{A RESPONSABILIDADE ENUNCIATIVA: NOÇÕES FUNDAMENTAIS}

Adam (2008), ao propor a categoria da responsabilidade enunciativa, postula que as ações, as representações discursivas são pontos de vista (doravante, PdV). Conforme o autor, as ações relatadas são ligadas entre si pelo ponto de vista, sendo que esse é, geralmente, marcado por introdutores como segundo, de acordo com, para, em Washington, em Paris. Esses exemplos de formas de introduzir "[...] marcam uma zona textual sob a dependência de uma fonte de saber (mediação epistêmica) ou de percepção (mediação perceptiva)" (ADAM, 2008, p. 115).

Desse modo, na construção de textos, existem enunciados não assumidos pelo locutor-enunciador. Tais enunciados são atribuídos a um outro enunciador, a uma outra fonte de saber. Adam (2008) mostra que existem variados recursos linguísticos que funcionam na atribuição de enunciados a outros e, também, recursos que servem para assinalar que o locutor-enunciador assume a responsabilidade pelo $\mathrm{PdV}$ enunciado.

Uma questão colocada por Adam (2008) diz respeito à extensão do enunciado atribuído a um outro PdV. Em outras palavras, a preocupação do autor é saber como identificar as fronteiras entre o que pertence ao locutor-enunciador do texto e o que pertence ao PdV de um outro enunciador, a uma outra fonte de saber introduzida no texto. Nessa discussão, Adam (2008) nos mostra que as 
aspas funcionam, por exemplo, como recurso linguístico na delimitação das fronteiras. A abertura e o fechamento das aspas facilitam a delimitação dos enunciados não assumidos pelo locutor-enunciador e, ao mesmo tempo, delegam a responsabilidade a um outro.

Ademais, em Adam (2008), as categorias que materializam a responsabilidade enunciativa são: (i) os índices de pessoa; (ii) os dêiticos espaciais e temporais; (iii) os tempos verbais; (iv) as modalidades; (v) os diferentes tipos de representação da fala; (vi) as indicações de quadros mediadores; (vii) os fenômenos de modalização autonímica; e (viii) as indicações de um suporte de percepções e de pensamentos. Essas categorias advêm de trabalhos que nem sempre pertencem a uma mesma abordagem teórica. Isso já é indicado pelo próprio Adam (2008), quando menciona, em cada categoria, a base teórica que fundamenta cada uma delas.

A título de exemplo, citamos a categoria denominada como os diferentes tipos de representação da fala, que encontra embasamento teórico em Mikhail Bakhtin e em estudos, por exemplo, de Dominique Maingueneau. Já a categoria denominada as indicações de quadros mediadores tem como referente teórico principal os estudos de Slatka Guentchéva e Jacqueline Authier-Revuz. Por sua vez, a categoria as indicações de um suporte de percepções e de pensamentos encontra respaldo nos estudos de Gilles Philippe e Gabriel Bergounioux. Quanto à categoria os fenômenos de modalização autonímica esta está inscrita nos estudos linguístico-enunciativos de Jacqueline Authier-Revuz. Discutiremos essa última categoria no próximo tópico, já que o presente trabalho investiga a nãocoincidência interdiscursiva como marca da responsabilidade enunciativa.

\subsection{O FENÔMENO DA MODALIZAÇÃO AUTONÍMICA E A NÃO-COINCIDÊNCIA INTERDISCURSIVA}

Ao citar a modalização autonímica como recurso que marca a responsabilidade enunciativa, Adam (2008) aponta os estudos enunciativos de Authier-Revuz (1998; 2004), sinalizando uma exterioridade teórica. Desse modo, estudar a responsabilidade enunciativa, a partir do fenômeno da modalização autonímica, é trazer para discussão duas perspectivas teóricas que, nesse caso, complementam-se.

Assim, voltando nossa atenção para os estudos de Authier-Revuz (2004), constatamos que ela apresenta, esquematicamente, alguns mecanismos ou expressões denominadas de controle-regulagem do processo de comunicação. Essas expressões assinalam um ponto no discurso em que aflora a heterogeneidade, sendo, também, denominadas pela autora de formas de modalização autonímica e, mais precisamente, de as não-coincidências do dizer (doravante NCD).

Authier-Revuz (1998; 2004) lista quatro tipos ou pontos de NCD: (i) pontos de não-coincidência interdiscursiva; (ii) pontos de não coincidência interlocutiva; (iii) pontos de não-coincidências entre as palavras e as coisas; e (iv) pontos de não-coincidências das palavras com elas mesmas. Segundo Authier-Revuz (2004), as categorias (i) e (ii) têm como base o dialogismo bakhtiniano e a interdiscursividade de Pêcheux; já as categorias (iii) e (iv) têm como base o discurso teórico da psicanálise freudo-lacaniana. Cabe dizer que essas quatro categorias enunciativas possuem vários formatos linguísticos e se desdobram em sub-categorias diversas, além de apresentarem diversas funções discursivas na construção de sentidos do texto/discurso. Das quatro NCD citadas acima, como já dito, voltaremos nossa atenção para a primeira.

Segundo Authier-Revuz (1998), a não-coincidência interdiscursiva permite especificar tipos de fronteiras entre si e o outro, conduzindo o discurso a produzir uma imagem de si mesmo, por diferença, servindo, assim, como: (1) Balizagem ou incerteza (discurso citado e retomadas de outros discursos de forma não-marcada (como alusão)); (2) balizagem exterior "apropriada” ao objeto do dizer (palavras de um outro lugar, palavras de uma outra época, palavras de uma outra teoria, palavras de uma outra pessoa); (3) exterioridade de uma palavra ou do sentido de uma palavra (x, no sentido de); (4) especificação do tipo de outro (outra língua, outra região, outra época, outro registro, outro ‘socioleto', outro discurso teórico, outra posição política).

Ao comentar essa NCD, Authier-Revuz (2004, p. 24) explica que ela “[...] nomeia o outro-estrangeiro(a) e/ou frequentemente o traduzem ou o explicitam com as palavras normais do discurso". Esse tipo de não-coincidência do dizer é materializado por glosas que assinalam, no discurso, a presença de outras palavras, marcadas como pertencentes a um outro. 
Ademais, nos estudos de Authier-Revuz (1998; 2004), encontramos algumas formas de discurso citado/relatado que materializam a não-coincidência interdiscursiva, a saber: o discurso direto, o discurso indireto, a modalização em discurso segundo e o discurso indireto com ilhota textual.

No discurso direto (DD), temos a reprodução literal das palavras de um outro. Conforme Authier-Revuz (1998, p. 140), “[...] a mensagem citada em DD, em seu caráter autônimo, suspende a possibilidade de sinonímia: isso significa que a mensagem 'mostrada' em DD é dada em sua materialidade significante". Desse modo, o DD apresenta uma ruptura sintática em que recursos linguísticos delimitam fronteiras entre o discurso citado e o discurso citante.

Comparado ao discurso indireto, o discurso direto "[...] não enuncia um conteúdo como o DI, ele mostra uma cadeia significante" (AUTHIER-REVUZ, 2004, p.140). Desse modo, o DD apresenta uma estrutura sintática heterogênea em que o discurso do um apresenta as próprias palavras do outro. Por outro lado, no discurso indireto (DI) "[...] o enunciador relata um outro ato de enunciação e usando suas próprias palavras, pelas quais ele reformula as palavras de outra mensagem: o modo semiótico do DI é, de maneira homogênea, o modo-padrão" (AUTHIER-REVUZ, 1998, p.139, grifo da autora). Assim, no discurso indireto temos a reformulação de um outro discurso em que os sentidos, o conteúdo do outro são citadas, mas não com as mesmas palavras, ou seja, o significante não é reproduzido.

Além do DD e do DI, Authier-Revuz (1998, p. 142) cita também casos em que no DI se constata a presença de um "[...] elemento como 'não traduzido', como fragmento conservado da mensagem de origem". Esse elemento é denominado de ilhota textual. Nesse caso, temos um discurso indireto comportando uma ilhota textual de discurso direto entre aspas ou marcado com itálico. A ilhota textual é considerada uma "forma híbrida" ou "mista” por ser uma associação de DD e DI (AUTHIER-REVUZ, 2004).

Authier-Revuz (1998) apresenta, ainda, a modalização em discurso segundo. Nesse tipo, temos um modalizador que faz referência a um outro discurso. Uma das características desse tipo de discurso relatado é que ele faz recair sobre o outro a responsabilidade pelo conteúdo do enunciado. Além disso, a modalização em discurso segundo apresenta como introdutores modalizadores como segundo, para, conforme, que remetem a um outro discurso, a uma outra fonte. Conforme Authier-Revuz (1998), a modalização em discurso segundo é caracterizada, ainda, por depender de um outro discurso, apresentando-se como sendo ela mesma como segunda.

Por fim, a não-coincidência interdiscursiva evidencia o fenômeno do dialogismo materializado no discurso, visto que traz as várias vozes que circulam no meio social para instaurar sentidos. Esse coral de vozes que circula e penetra o discurso faz com que o enunciador, o 'eu' de um dizer, tenha que reconhecer, marcar, o seu dizer em relação ao dizer de outros, ou em relação ao dito de uma teoria, ou em relação ao dito em uma outra época.

\section{A NÃO-COINCIDÊNCIA INTERDISCURSIVA COMO MARCA DA RESPONSABILIDADE ENUNCIATIVA NO TEXTO MONOGRÁFICO}

A leitura das dez seções de revisão bibliográfica de monografias de conclusão de curso de Letras mostra a significativa ocorrência da não-coincidência interdiscursiva. Quanto a isso, considerando os achados da pesquisa de forma mais ampla, cabe esclarecer que, dos pontos de não-coincidências do dizer identificados, $92 \%$ dos casos são de não-coincidência interdiscursiva. A não-coincidência interlocutiva aparece com $5 \%$ de recorrência; a não-coincidência entre as palavras e as coisas com $2 \%$; e a não-coincidência das palavras consigo mesmas com 1\%. Essas informações são importantes para percebermos a relevância da não-coincidência interdiscursiva na construção de sentidos do texto monográfico.

Conforme já dito, a não-coincidência interdiscursiva, assim como as demais, materializa-se por meio de vários recursos linguísticoenunciativos. Assim, de acordo com a análise empreendida, constatamos que a não-coincidência interdiscursiva ocorre por meio de recursos como discurso citado direto (75\%), discurso citado indireto (15\%), discurso citado indireto com ilhota textual (3\%), 
modalização em discurso segundo (6\%) e especificação de um tipo de outro: outra língua (1\%). Diante desse achado e visando a análise, selecionamos recortes discursivos do corpus que melhor representassem cada um desses recursos. Pretendemos, desse modo, para efeito de análise, apresentar ocorrências representativas, já que, em decorrência do tempo-espaço, não teríamos como analisar minunciosamente cada uma das ocorrências materializadas no corpus. Vejamos o excerto [1], abaixo.

\section{[01] Discurso citado direto}

De acordo com os postulados da Linguística Textual, concebia-se inicialmente que, para ser aceita como texto, uma dada manifestação linguística deveria submeter-se a um conjunto de critérios de textualidade, o que seja, segundo Costa Val (1994, p. 05): "o conjunto de características que fazem com que um texto seja um texto e não apenas uma sequência de frases". Assim sendo, entendemos que a noção de textualidade parte do princípio de que toda interação comunicativa apresenta, necessariamente, a característica da textualidade, ou seja, realiza-se sob a forma textual. (M01, p. 21)1.

Neste fragmento, constatamos que o estudante discute os critérios da textualidade, mostrando os avanços na concepção de texto ao longo dos estudos linguísticos. Para fundamentar seu dizer, o estudante recorre às palavras de Costa Val (1994, p. 05). Para isso, ele mobiliza um discurso citado direto, ou seja, ele reproduz fielmente as palavras de Costa Val, a saber: segundo Costa Val (1994, p. 05): "o conjunto de características que fazem com que um texto seja um texto e não apenas uma sequência de frases". De início, o fragmento em destaque apresenta um termo introdutor, segundo, que aponta, semanticamente, para uma não assunção da responsabilidade enunciativa pelo que vem depois dele. Na sequência, apresenta o nome de um outro autor, qual seja: Costa Val. Além disso, numa atitude de marcar temporalmente o discurso do outro, assinala o ano da publicação da obra e o número da página da qual retirou a citação, (1994, p. 05), seguindo, assim, as orientações dos manuais que regulam a produção de textos acadêmicos.

No entanto, do ponto de vista da ATD, não é somente isso que encontramos no fragmento em questão: esse ponto do discurso em evidência revela a presença de outra instância enunciativa, um discurso dito em uma outra circunstância por uma outra fonte do saber, que é mobilizado para criar certos efeitos de sentido. Adam (2008, p.115) nos diz que "[...] muito frequentemente, esses PdV são assinalados por introdutores como segundo"e, em outro ponto, explica que o marcador segundo indica que uma porção do texto não é assumida pelo locutor.

O excerto 01 apresenta, ainda, além dos aspectos já apontados, um trecho entre aspas. As aspas exercem um papel significativo nos estudos acerca da responsabilidade enunciativa. Conforme Adam (2008), as aspas delimitam um segmento de texto sob a dependência de uma outra fonte do saber, ou seja, as aspas delimitam, marcam uma porção do texto que não é assumida pelo autor, mas que é atribuída a uma outra fonte. No caso em análise, a porção do texto entre aspas foi atribuída à Costa Val. Ao colocar um fragmento de texto entre aspas, o estudante sinaliza para o leitor, como que dizendo: essas palavras não são minhas. Ao fazer uso das aspas, o estudante-enunciador mobiliza uma forma de dizer para marcar que o discurso pertence a um outro, sendo, portanto, ético na escrita do texto acadêmico, não assumido como seu um enunciado dito por um outro enunciador.

Explorando mais ainda o fragmento 01, é possível perceber que embora as palavras reproduzidas em discurso citado direto não tenham sido assumidas pelo estudante como sendo de sua autoria, esse discurso não é citado de forma aleatória. Ou seja, o discurso citado direto exerce uma função dentro do texto monográfico em análise, sendo um suporte, uma base de sustentação para que, a partir dele, o estudante enuncie, reflita, interprete. Estamos, nessa perspectiva, diante de um dos aspectos do dialogismo materializado na tessitura textual.

Ademais, pensando a expressiva recorrência do discurso citado direto, percebemos que o estudante, na construção do texto monográfico, tende a construir um apagamento do seu dizer. Evidentemente, isso é um efeito de sentido, tendo em vista as orientações e os discursos que direcionam o estudante para uma escrita marcada por outros discursos. Nesse sentido, construir uma

${ }^{1}$ Utilizamos códigos para identificar cada Monografia. Assim, por exemplo, o código M01, p.21 corresponde à primeira Monografia codificada e o número da página de onde foi extraído o fragmento. 
monografia implica mobilizar vozes diversas, explicitando-as no texto e, ao mesmo tempo, silenciar a própria voz. Isso porque, na seção teórica do gênero monografia, o que importa é o que o outro diz (já disse) sobre determinada temática.

Passemos ao discurso indireto, conforme o exemplo em [2]:

\section{[02] Discurso citado indireto}

Bezerra (2005) afirma que, para que a escola desenvolva a competência comunicativa, é preciso priorizar o trabalho com os gêneros discursivos, já que estes são responsáveis pela articulação entre as práticas sociais e a escola não pode reduzir o trabalho com gêneros aos aspectos estruturais ou formais dos textos. (M02, p.16)

O fragmento 02 mostra a ocorrência de uma forma de discurso citado indireto (DI) como marcador de responsabilidade enunciativa. Cabe lembrar que, no DI, "[...] o enunciador relata um outro ato de enunciação e usando suas próprias palavras, pelas quais ele reformula as palavras de outra mensagem." (AUTHIER-REVUZ, 2004, p. 139). No caso em análise, o enunciador discorre acerca da importância de a escola trabalhar com os gêneros discursivos para desenvolver as competências comunicativas dos alunos e cita, por meio de um discurso indireto, Bezerra (2005). Ele não reproduz literal as palavras de Bezerra, mas reformula os dizeres da pesquisadora. Nas palavras de Authier-Revuz (2004, p. 151): "O DI, corresponde a uma operação de reformulação, isto é, de produção de um enunciado como tendo o mesmo sentido que $m$ do ato relatado". Em outras palavras, o discurso citado indireto é uma reformulação em que os sentidos de um outro texto são reproduzidos, mas não suas palavras, ou seja, o significante. Nesse sentido, após os introdutores Bezerra (2005) afirma que, todo o segmento é a reformulação de um outro enunciado que teve apenas os sentidos reproduzidos, mas não o significante, a forma literal.

Vale frisar a função exercida pelos introdutores destacados. Esses estão organizados da seguinte forma: nome do autor + ano da publicação da obra + verbo dicendi + que. O uso dessa estrutura linguística introduz uma reformulação, revelando certa competência por parte do enunciador em parafrasear o discurso do outro. No entanto, embora ele seja responsável por refazer a estrutura textual, não assume a autoria dos sentidos nela expressos. Em outros termos, o estudante é responsável pelo enunciado aqui e agora, pela reformulação do discurso, mas não se coloca como o autor, a fonte dos sentidos reproduzidos. Tal movimento discursivo cria um efeito argumentativo que, ao mesmo tempo em que atribui o dizer a um outro autor, utiliza esse dizer como discurso de autoridade na construção do texto.

Diante dos casos de discurso citado indireto, vale frisar que, quando falamos de responsabilidade enunciativa, não estamos falando apenas de palavras literais (significante), mas sim, principalmente, de pontos de vista. Não é apenas de frase (gramatical), mas de texto/discurso (sentido). O DI, portanto, por indicar a reformulação de um outro texto, conservando o sentido desse, se configura como uma marca da não-coincidência do discurso consigo mesmo e, por conseguinte, da responsabilidade enunciativa. No DI, temos a presença de um outro ato enunciativo, de um outro discurso, de um outro autor, de uma outra fonte do saber. Assim, a responsabilidade enunciativa é marcada pelo fato de que, ao utilizar um DI, o autor atribui a responsabilidade pelo conteúdo expresso a um outro, a uma outra fonte do saber.

Passemos aos casos em que surge a ilhota textual.

[03] Discurso citado indireto com ilhota textual

Maingueneau afirma que, para a boa compreensão de um texto, é necessário "encarná-lo", observar a relação entre o texto e os discursos. [...] (M03, p. 16)

No fragmento 03, uma ilhota textual marca um ponto de não-coincidência do discurso consigo mesmo, assinalando a responsabilidade enunciativa. No caso em tela, um discurso citado indireto tem como introdutor a expressão Maingueneau afirma que. O estudante recorre, desse modo, ao ponto de vista de Maingueneau acerca da compreensão de texto, de como o leitor deve proceder diante dos textos, reformulando-o da seguinte forma: Maingueneau afirma que, para a boa compreensão de um texto, é 
necessário "encarná-lo", observar a relação entre o texto e os discursos. O ponto que destacamos desse fragmento em DI é o seguinte: dentro desse DI constatamos a expressão, encarná-lo, que foi destacada entre aspas, configurando-se, assim, uma ilhota textual. De acordo com Authier-Revuz (1998, p. 194), na ilhota textual temos um elemento do texto como tendo "resistido" "[...] na sua literalidade à operação de reformulação - tradução".

A ilhota textual se configura como uma marca da não-coincidência interdiscursiva e, consequentemente, da responsabilidade enunciativa pelo fato de marcar, no fio do discurso, palavras que pertencem a um outro discurso. Para Authier-Revuz (1998), a ilhota textual é uma "forma híbrida" ou "mista" de discurso relatado, isso porque ela associa duas formas de discurso, a saber: DD e DI. No fragmento 03, portanto, temos o uso de um discurso indireto comportando uma ilhota textual de discurso direto entre aspas. Nesse sentido, tanto o discurso indireto apresenta um ponto de vista pertencente a uma outra fonte, quanto o fragmento entre aspas (ilhota textual) marca palavras pertencentes a um outro autor.

A seguir, analisemos ocorrências de modalização em discurso segundo, conforme o excerto em [04]:

[04] A modalização em discurso segundo

Segundo os PCN's (1998), se faz necessário valorizar a linguagem e seus usos estabelecidos pela sociedade a cada momento. Sendo assim, existe a necessidade de uma revisão dos métodos de ensino e a constituição de práticas que possibilitem ao aluno ampliar a dimensão interacional e discursiva. (M02, p. 18)

O fragmento 04 mostra uma ocorrência da modalização em discurso segundo como forma de discurso relatado - na terminologia de Authier-Revuz (1998). No caso em questão, o estudante recorre aos PCN’s (1998) numa discussão acerca do valor que se deve dar à linguagem em seus usos estabelecidos pela sociedade. Assim, o enunciado introduzido por Segundo os PCN's (1998) está sob a dependência de um outro ponto de vista, apresentando uma outra fonte enunciativa.

Com relação às formas introdutoras do tipo segundo, Authier-Revuz (1998, p.135) afirma que elas inscrevem-se "[...] num paradigma de elementos modalizadores diversos, cuja especificidade, em seu interior, é a de modalizar pela referência a um outro discurso". No caso em tela, o enunciado que se encontra introduzido por segundo os PCN's (1998) tem seu sentido remetido a essa outra fonte do saber. Nesse caso, o estudante opera uma atividade de parafraseamento do dizer do outro.

Além disso, é importante dizer que a modalização em discurso segundo faz recair sobre outro o conteúdo da afirmação de um enunciado, conforme postula Authier-Revuz (1998). Assim, nesse tipo de discurso citado, não são as palavras que são atribuídas a outrem, mas, sim, o conteúdo do discurso. É nesse ponto que a responsabilidade enunciativa se manifesta, isso porque se faz presente o ponto de vista do outro.

Por último, passemos aos casos de especificação do tipo de outro, mais precisamente outra língua, a partir do exemplo em [05]:

[05] Especificação do tipo de outro: Outra língua

Os objetos que simbolizam status são, de acordo com Bosi (2003), objetos que a moda valoriza, não se enraízam nos interiores e nem envelhecem com o dono, apenas se deterioram. [...]" (M05, p.30)

No fragmento 05, constatamos o uso de uma palavra de uma outra língua, a saber: status. O estudante-enunciador faz uso do itálico para marcar essa palavra como pertencente a uma outra língua, configurando, desse modo, uma não-coincidência do discurso consigo mesmo. Ao destacar essa palavra em seu discurso, o estudante-enunciador está delimitando fronteiras entre o interior e o exterior ao seu discurso. É, além disso, o encontro de duas línguas. Em outras palavras, é uma forma de dizer que aquela palavra não pertence à mesma língua na qual seu discurso está sendo produzido, sendo, também, um termo técnico. 
Podemos aplicar a esse fragmento 05 os comentários de Authier-Revuz (1998) acerca da não-coincidência interlocutiva, quando ela explica que, ao assinalar entre suas palavras a presença estranha de palavras marcadas como pertencendo a um outro discurso, um discurso esboça em si o traçado - assinalando uma 'interdiscursividade representada' - de uma fronteira interior/exterior. No caso em análise, temos o exterior marcado em itálico, especificando a fronteira entre o um e o outro - a outra língua.

Os fragmentos analisados, portanto, mostram ocorrências do fenômeno da modalização autonímica, mas especificamente da nãocoincidência interdiscursiva. Eles revelam casos de discurso citado direto, discurso citado indireto, discurso citado indireto com ilhota textual, modalização em discurso segundo, entre outros. Todas esses recursos materializam a responsabilidade enunciativa, já que em um determinado ponto do texto/discurso, emerge um outro discurso, outro ponto de vista, uma outra fonte do saber.

Os sentidos do texto monográfico são construídos no movimento discursivo de reprodução do discurso do outro, de reformulação, parafraseamento, na relação de acordo com o dito do outro, no jogo de atribuição e/ou assunção de pontos de vista. É nesse jogo dialógico que os sentidos são construídos, materializando-se por meio de mecanismos linguístico-enunciativos. A não-coincidência interdiscursiva, como marcas da responsabilidade enunciativa, atua no texto monográfico de modo a promover um diálogo com o outro na tessitura textual, em um jogo de atribuição e/ou de assunção de pontos de vista. Em todos os casos analisados, constatamos que a responsabilidade enunciativa se configura como elemento presente na construção de sentido do texto monográfico.

\section{CONCLUSÃO}

Neste artigo, centramos nosso interesse na investigação da responsabilidade enunciativa em seções de revisão da bibliografia de monografias de conclusão de curso, focando a análise, mais precisamente, na não-coincidência interdiscursiva (fenômeno de modalização autonímica/as não-coincidência do dizer) como categoria de análise. A partir desse propósito, estabelecemos como objetivo identificar, descrever e analisar a não-coincidência interdiscursiva como ponto que assinala a responsabilidade enunciativa. Para isso, mobilizamos pressupostos teórico-metodológicos da ATD, mais precisamente, baseamo-nos em estudos de Adam (2008), recorrendo aos postulados de Authier-Revuz $(2004 ; 1998)$ como exteriores teóricos apontados por Adam para abordar o fenômeno da não-coincidência interdiscursiva.

Desse modo, constatamos que a não-coincidência interdiscursiva foi materializada por meio de: (a) discurso citado direto, (b) discurso citado indireto, (c) modalização em discurso segundo, (d) discurso citado indireto com ilhota textual, (e) outra língua. Considerando a significativa recorrência dos vários mecanismos de materialização da não-coincidência interdiscursiva, em que temos a especificação dos tipos de fronteiras entre discursos, ou seja, temos a presença dos outros discursos no discurso, constatamos os vários modos pelos quais a língua registra o diálogo materializado na trama discursiva, convergindo para a construção dos sentidos do texto.

Ademais, e em decorrência do aspecto anterior, constatamos que a seção de revisão da bibliografia de monografia de conclusão de curso é construída na dependência de um outro ponto de vista, de um outro dizer, de um outro discurso, sendo essa seção um espaço de vários pontos de vista e que esses, na maioria das vezes, não são assumidos pelo estudante/produtor. Em outras palavras, os dizeres/conceitos/ideias/teses são trazidos para a construção da Monografia, mas a responsabilidade pelo seu conteúdo não é assumida pelo estudante, nos termos propostos por Adam (2008). O jogo entre atribuição e/ou assunção de pontos de vista faz parte, portanto, da natureza do gênero monográfico. É nesse jogo que os sentidos são construídos. É atribuindo ao outro os pontos de vista expressos que o estudante mantém o diálogo com os estudiosos de determinada área do conhecimento, sendo essa uma necessidade do texto acadêmico.

Cabe ressaltar, por fim, que este trabalho, ao tomar a não-coincidência interdiscursiva como categoria de análise da responsabilidade enunciativa, abarca apenas um viés possível de análise. Nesse sentido, a responsabilidade enunciativa, sendo um fenômeno que pode ser marcado por meio de vários elementos linguísticos, encontra na não-coincidência interdiscursiva apenas uma das muitas formas de ser analisada. 
Assim, a presente investigação possibilita uma abertura para que outros trabalhos sejam empreendidos no sentido de investigar, no âmbito dos estudos da ATD, a responsabilidade enunciativa, fazendo dialogar correntes teóricas diversas. Além disso, devido à necessidade da delimitação, este estudo foi desenvolvido tomando como corpus de análise apenas as seções de revisão da bibliografia de monografias de conclusão de Curso de Letras. Isso implica dizer que abordagens semelhantes podem ser desenvolvidas, observando as demais seções desse gênero e, também, outros gêneros discursivos produzidos em outras situações de produção.

\section{REFERENNCIAS}

ADAM, J. M. A linguística textual: introdução à análise textual dos discursos. Tradução de Maria das Graças Soares Rodrigues et al. Revisão técnica de Luis Passeggi e João Gomes das S. Neto. São Paulo: Contexto, 2008.

AUTHIER-REVUZ, J. Palavras incertas: as não-coincidências do dizer. Tradução de Claudia R. Castellanos Pfeiffer et al. Revisão técnica de Eni Pulccinelli Orlandi Campinas: Ed. da UNICAMP, 1998.

. Heterogeneidade mostrada e heterogeneidade constitutiva: elementos para uma abordagem do outro no discurso.

In:_____Entre a transparência e a opacidade: um estudo enunciativo do sentido. Apresentação Marlene Teixeira. Revisão técnica de Leci Borges Barbisan e Valdir do Nascimento Flores. Porto Alegre: EDIPUCRS, 2004. p. 11-80.

BOCH, F; GROSSMANN, F. Referir-se ao discurso do outro: alguns elementos de comparação entre especialistas e principiantes. Scripta, Belo Horizonte, v.6, n.11, p. 97-108, 2002.

BESSA, J. C. R. Referência ao discurso do outro: uma análise de problemas de relações de sentido entre discurso citado direto e discurso citante no gênero monográfico. 110 f. Dissertação (Mestrado em Estudos da linguagem) - Programa de Pós-graduação em Estudos da Linguagem, ligado ao Centro de Ciências Humanas, Letras e Artes, Universidade Federal do Rio Grande do Norte, Natal, 2007.

; BERNARDINO, R. A. dos S. Das marcas de dialogismo no texto acadêmico: o discurso citado em monografias de estudantes de Letras/Português. In: Revista Língua \& Literatura, Frederico Westphalen, v. 13, n. 21, p.55-76, dez. 2011. Disponível $\mathrm{em}<\mathrm{http}: / /$ revistas.fw.uri.br/index.php/revistalinguaeliteratura/article/view/163 > Acesso em: 25 maio. 2012.

BERNARDINO, R. A. dos S. A reformulação parafrástica na fundamentação teórica de trabalhos de conclusão do curso de Letras. 2009. 152 f. Dissertação (Mestrado em Estudos da linguagem) - Programa de Pós-graduação em Estudos da Linguagem, Universidade Federal do Rio Grande do Norte, Natal, 2009.

FONSECA, A. F. da; RODRIGUES, M. das G. S. A responsabilidade enunciativa em discurso de posse do presidente Lula. In: CONGRESSO BRASILEIRO DE LINGUÍSTICA APLICADA, 9, 2012, Rio de Janeiro. Anais... Rio de Janeiro: UFRJ, 2012. Disponível em: < http://www.alab.org.br/pt/eventos/ix-cbla/129> Acesso em: 04 abr. 2012.

MATENCIO, M. de L. M. Atividades de re (textualização) em praticas acadêmicas: um estudo do resumo. Scripta, Belo Horizonte, v. 1, n. 1, p. 109-122, 1997.

OLIVEIRA, J. de. A responsabilidade enunciativa nas telenovelas: por uma leitura crítica. In: SIMPÓSIO INTERNACIONAL DE LETRAS E LINGUÍSTICA, 2011, Uberlândia, v. 2, n. 2. Anais... Uberlândia: EDUFU, 2011. p.1-10. Disponível em: < www.ileel.ufu.br/anaisdosilel/pt/arquivos/silel2011/1261.pdf >. Acesso em: 10 abr. 2012.

PEREIRA, C. C. Formas e funções do discurso do outro no gênero monográfico. $234 \mathrm{f}$. Dissertação (Mestrado em Estudos da linguagem) - Programa de Pós-graduação em Estudos da Linguagem, Universidade Federal do Rio Grande do Norte, Natal, 2007. 
PASSEGGI, L. et al. A análise textual dos discursos: para uma teoria da produção co(n)textual de sentido. In: BENTES, A. C.; LEITE, M. Q. (Org.). Linguística de texto e análise da conversação: panorama de pesquisas no Brasil. São Paulo: Cortez, 2010. p. $262-312$.

RODRIGUES, M. das. G. S. Gêneros discursivos acadêmicos: de quem é a voz? In: SIMPÓSIO MUNDIAL DE ESTUDOS DE LÍNGUA PORTUGUESA, 2, 2009, Évora. Anais... Évora: Universidade de Évora, 2009.Disponível em: <http://www.simelp2009.uevora.pt/slgs/slg26.html>. Acesso em: 01 ago. 2011.

SANTOS, J. P. dos. Análise textual dos discursos: a responsabilidade enunciativa em textos de alunos iniciantes de Letras. In: CONGRESSO BRASILEIRO DE LINGUÍSTICA APLICADA, 9, 2012, Rio de Janeiro. Anais... Rio de Janeiro: UFRJ, 2012. Disponível em: < http://www.alab.org.br/pt/eventos/ix-cbla/129>. Acesso em: 04 abr. 2012. 